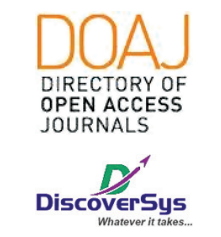

Published by DiscoverSys

\section{Level of awareness of alzheimer's disease among elderly people in Denpasar, Bali}

\author{
Sabrina Annamma Philip, ${ }^{1 *}$ Desak Made Wihandani, ${ }^{2}$ Ni Nyoman Ayu Dewi ${ }^{2}$
}

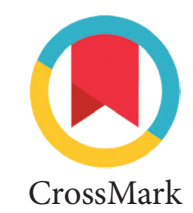

CrossMark

\title{
ABSTRACT
}

Background: Alzheimer's disease (AD) is a chronic, irreversible, progressive, neurodegenerative that slowly impair memory and thinking skills especially in elderly people. This study aims to determine the level of awareness of $A D$ among elderly people in Denpasar, Bali.

Methods: A descriptive cross-sectional study was conducted by using self-administered validated questionnaire to determine the level of awareness of Alzheimer's disease among the elderly people in Denpasar, Bali. The level of awareness could be classified into high awareness (>80\%), moderate awareness (50-79\%) and low awareness $(<50 \%)$
Results: There were 50 subjects with 50 years old or above enrolled in this study. Most of the respondents had low awareness (82\%) to the AD. About $38 \%$ of elderly people knew about $A D$ and $58 \%$ of respondents said losing memory is a common thing in old age. Low education was said responsible increasing the risk of $A D(30 \%)$. Only about $24 \%$ answered depression was prone to $A D$. In addition, about $34 \%$ said there was no cure for Alzheimer's disease.

Conclusion: Level of awareness among elderly people towards Alzheimer's disease was low and needed improvement. Development and execution of educational programs should be carried out to the public to expand knowledge and understanding about Alzheimer's disease.
'Undergraduate Student, Faculty of Medicine, Universitas, Denpasar, Bali

${ }^{2}$ Biochemistry Department, Faculty of Medicine, Universitas Udayana, Denpasar, Bali
*Correspondence to: Sabrina Annamma Philip; Undergraduate Student, Faculty of Medicine, Universitas, Denpasar, Bali; sabzwitch@gmail.com

Received: 2018-04-16 Accepted: 2018-05-07 Published: 2020-03-27

Keywords: Alzheimer's disease, Elderly people, Level of Awareness.

Cite This Article: Philip, S.A., Wihandani, D.M., Dewi, N.N.A. 2020. Level of awareness of alzheimer's disease among elderly people in Denpasar, Bali. Intisari Sains Medis 11(1): 268-271. D0I: 10.15562/ism.v11i1.260

\section{INTRODUCTION}

Alzheimer's disease (AD) is ranked as the sixth leading cause of death in the United States and the most prevalent neurodegenerative disorder in the world. Approximately 47 million people are affected by this disease and the number predicted will be increased $62 \%$ by 2030 . $^{1}$ The disease was named after Dr. Alois Alzheimer found that elderly people usually had problems related to memory, thinking, and behavior. ${ }^{2} \mathrm{AD}$ is an irreversible, progressive brain disorder that slowly impairs memory and thinking skills. ${ }^{2}$ In most people with $\mathrm{AD}$, the first symptoms appear in their mid-60s as dementia could be the most prominent. The biochemistry of $\mathrm{AD}$ is one of the most common causes of adult dementia. Several studies proved that the etiology of AD caused by the protein misfolding or proteopathy due to the accumulation of abnormally folded amyloid beta protein in the brains of Alzheimer's patients., ${ }^{2,3}$

Scientists have identified three known risk factors for $\mathrm{AD}$ such as age, gender, and genetics. The most significant and reliable risk factor of all is age. Growing old is the higher the risk of developing AD. Alzheimer's is not a part of normal aging, but the risk increases significantly after 65 years old. ${ }^{4}$ The disease interrupts the information transmission from neuron to neuron, eventually leading to the death of synaptic connections and significant shrinkage of the brain. ${ }^{4}$ There is no definitive treatment for Alzheimer's Disease, but there are treatments that can reduce the symptoms and improve the quality of life for those with $\mathrm{AD}$ and their caregivers. ${ }^{4}$

With the dramatically increasing contribution of $\mathrm{AD}$ worldwide, many countries are being urged to address this as a public health priority. There are as many as 7.7 million new cases of the disease, which means that every four seconds a new case of $\mathrm{AD}$ is emerged. ${ }^{5}$ In Indonesia, there are about twenty million adults at risk for AD. There are no data on AD's prevalence in Indonesia except in Jakarta. There are approximately 1 million cases of AD estimated in 2011. ${ }^{5}$ The prevalence in Jakarta is about $3.5 \% .^{6}$ Poor awareness and lack of family support lead to inappropriate recognition and management of $\mathrm{AD}$ in health service. According to the explanation above, this study aims to determine the public belief and knowledge about the level of awareness of Alzheimer's disease among the elderly people in Bali

\section{METHODS}

\section{Study Design and Data Collection}

A cross-sectional study design was carried out among 50 elderly people in Denpasar, Bali by using simple random sampling. The study was conducted by using self-administered validated questionnaire 
and interview at Dharma Laksana Association and Renon Park among the elderly people in Denpasar Bali. The respondents who participate in this study must be older than 50 years old according to WHO. ${ }^{7}$

The technique used to obtain adequate data was by distributing questioners. Questioners were inclued by written statements The respondents had to participate honestly and answer the questions based on their understanding. The respondents also already sign informed consent.

\section{Data description}

Knowledge could be measured by calculate the number of answer correctly towards Alzheimer's related questions. Then, the level of awareness of $\mathrm{AD}$ was obtained by interviewing the elderly people based on the questionnaire. High awareness was evaluated if there are above $80 \%$ among correct answers. Besides that, moderate awareness was the among of correct answers obtained between 50 to 70 percent and for low awareness was the correct answers obtained below 50 percent.

\section{Data Analysis}

The primary data were collected from respondents. Data thus collected and analyzed descriptively by showing percentage and frequency on the table. The narrative explanation was also included in the results.

\section{RESULTS}

\section{Sample characteristics}

There were 50 respondents enrolled in this study with age 50 years or above at Dharma Laksana

Table 1 Sample Characteristic of elderly people in Bali

\begin{tabular}{lcc}
\hline Characteristics & Frequency & Percentage (\%) \\
\hline Age (year) & 22 & 44 \\
$50-55$ & 27 & 54 \\
$56-75$ & 1 & 2 \\
$>75$ & & \\
Gender & 18 & 64 \\
Male & 32 & 36 \\
Female & & \\
\hline
\end{tabular}

Table 2 Alzheimer's disease knowledge among elderly people in Denpasar, Bali

\begin{tabular}{lcc}
\hline Level of Awareness & Frequency & Percent \\
\hline High Awareness & 1 & 2 \\
Moderate Awareness & 8 & 16 \\
Low Awareness & 41 & 82 \\
Total & 50 & 100 \\
\hline
\end{tabular}

Association and Renon Park. Table 1 shows that the majority respondents are from the range group 56-75 (54\%), followed by 50-55 years-age group (44\%) and more than 75 years-age group (2\%). According to the gender, there were 32 females (64\%) and 18 males (36\%) participated in this study (Table 1).

\section{Knowledge and Level of Awareness among Respondents about AD}

Four general questions have been asked during the interview to know the knowledge of them. The results suggest that about $48 \%$ elderly people have problem with their memory. All the interviewed elderly people are not suffering from AD. All of them are healthy and they have mild memory problem. However, there were $8 \%$ of them answered that they have a family history with memory problem. From them, about $22 \%$ said that they know the risk factors.

According to the level of awareness, the study found that there were $2 \%$ elderly people had high awareness about $\mathrm{AD}$, followed by $16 \%$ and $82 \%$ of elderly people have moderate and low awareness respectively.

\section{DISCUSSION}

Alzheimer's disease is an irreversible, progressive, neurodegenerative disease that destroys the memory, thinking, and behavior. ${ }^{8}$ It is common in the elderly people community. The majority of the elderly people who enrolled in this study are in the age range of 56-75 years old. The results were also similar to the previous study conducted in Saudi Arabia where the majority respondents were in the 60-70 years age group. ${ }^{9}$

According to the results, $48 \%$ elderly people have a problem with their memory. In some cases, their memory power is not severely damaged. They tend to forget things like misplacing keys, forgetting stuff they have put and remembering dates that they have promised. ${ }^{10}$ It was similar to the previous study conducted by Jahn $\mathrm{H}$ where loss of memory as the first symptoms reported by patients who have Alzheimer's disease (AD) and by their caretakers. ${ }^{11}$

The level of awareness of Alzheimer's disease among elderly people in Bali is still poor and needs improvement. A study conducted by Jacus JP also suggested similar results where greater apathy and lower depression were associated with poorer awareness among elderly. ${ }^{12}$ However, in contrast with a study conducted by Ahlam Rasheed that revealed the perception of Saudi elderly people towards Alzheimer's disease was good and ranked as the first one. ${ }^{11}$ Level of awareness was higher 
among Saudi Arabian due to the community more educated and aware of this issue.

Based on the knowledge, the results of this study have a similar result with a study conducted by undergraduate nursing students at a Govt. College of Nursing. ${ }^{13}$ The previous study found that only $56 \%$ participants had inadequate knowledge of dementia related to Alzheimer's disease. ${ }^{13}$ The results suggest that the knowledge about Alzheimer's disease among the health service providers are also not satisfactory.

Some questions may be difficult for the elderly people to answer as they are not aware and they don't have enough information about this disease. Botucatu found that $91 \%$ of respondents had heard about Alzheimer's disease once, while some of them had primary concepts from media, others had well-founded scientific knowledge. ${ }^{14}$ However, the community-based cross sectional study in Aseer region, Saudi Arabia, found that $60 \%$ think that forgetfulness in elderly people is a part of aging process and does not need any medical consultation. The percentage between these two countries is similar and they have a similar perception about this issue. ${ }^{15}$

Low education increases the chance of getting Alzheimer's disease. Education could reduce the risk by building 'cognitive reserve' where a brain is stronger to counter neurological damage from the disease and by increasing the chances that people follow a healthier lifestyle. About 30\% said low education increases the risk of Alzheimer's disease and about $42 \%$ said no while $44 \%$ said they do not know. Data from the Canadian Study on Health and Aging shows that a lower level of education is associated with a higher risk of $\mathrm{AD}$ and vascular dementia. ${ }^{16}$

Furthermore, not many people are aware that depression is prone to the AD. Some symptoms of depression in someone who has Alzheimer's include apathy, loss of interest in activities, social withdrawing, isolation, trouble concentrating and impaired thinking. Only $24 \%$ answered depression is prone to Alzheimer's disease. About 54\% said depression is not prone to Alzheimer's and 22\% said they do not know. Depression and depression symptoms are common in persons with Alzheimer disease. When depression symptoms occur just before the development of Alzheimer's disease, they may be early symptoms of a dementing process. ${ }^{17}$ Nevertheless, a study conducted by Starkstein and colleagues found a correlation between apathy and depression with Alzheimer's disease in a longitudinal study. ${ }^{18}$

Alzheimer's disease has no definitive treatments, but there is prevention method that can reduce the risk of AD. Several ways such as helping people maintaining mental function, managing behavioral symptom and reducing certain problem can inhibit memory loss. The most important thing we can do towards the Alzheimer's people is by showing love and care to them. Based on the elderly people's understanding, about $34 \%$ said there is a cure for Alzheimer's disease while 38\% said there is no cure. Living a healthy lifestyle may help one's risk of developing Alzheimer's disease such as healthy eating, maintaining a healthy weight, regular exercise mentally and physically and most importantly participating in activities that involve socializing and stimulating brain activity. Connell and colleagues reported that $25.6 \%$ of respondents indicated making changes to their diet or lifestyle to avoid developing Alzheimer's disease. ${ }^{19}$

\section{CONCLUSION}

This study found that the awareness of the elderly people toward Alzheimer's disease is low and needs improvement. Development of educational programs should be carried out to the public to expand knowledge and understanding about Alzheimer's disease.

\section{CONFLICT OF INTEREST}

None.

\section{ETHICAL CONSIDERATION}

Ethics approval has been obtained from Ethics Committee of Universitas Udayana prior to the study being conducted.

\section{FUNDING}

None.

\section{AUTHOR CONTRIBUTION}

All of authors are equally contributed to the study from conceptual framework until reporting the results of study.

\section{REFERENCES}

1. Braak H, Del Tredici K. Alzheimer's pathogenesis: is there neuron-to-neuron propagation? Acta Neuropathol 2011;121(5):589-95.

2. O'Brien, R. and Wong, P. (2011). Amyloid Precursor Protein Processing and Alzheimer's Disease.Annu. Rev. Neurosci., 34(1), pp.185-204.

3. Williamson J, Goldman J, Marder K. Genetic Aspects of Alzheimer Disease. The Neurologist. 2009; 15(2):80-86. 
4. Friedman DB, Gibson A, Torres W, Irizarry J, Rodriguez J, Tang W, Kannaley K. Increasing Community Awareness About Alzheimer's Disease in Puerto Rico Through Coffee Shop Education and Social Media. J Community Health. 2016; 41(5):1006-12

5. Vinters HV. Emerging concepts in Alzheimer's disease. Annu. Rev. Pathol. Mech. Dis. 2015. 10:291-319

6. Wu YT, Brayne C, Matthews FE. Prevalence of dementia in East Asia: a synthetic review of time trends. Int J Geriatr Psychiatry. 2015; 30(8): 793-801.

7. Qiu C, Kivipelto M, Strauss EV. Epidemiology of Alzheimer's disease occurrence, determinants, and strategies toward intervention. Dialogues Clin Neurosci. 2009; 11(2): 111-128

8. Alzheimer's Association. Alzheimer's disease facts and figures. Alzheimers Dement 2014;10(2):47-92.

9. Rasheed SP. Self-Awareness as a Therapeutic Tool for Nurse/Client Relationship. International Journal of Caring Sciences. 2015; 8(1); 211-216

10. Toyota $\mathrm{Y}$, Ikeda $\mathrm{M}$, Shinagawa $\mathrm{S}$, Matsumoto $\mathrm{T}$, Matsumoto N, Hokoishi K, Fukuhara R, Ishikawa T, Mori T, Adachi H, Komori K, Tanabe H. Comparison of behavioral and psychological symptoms in early-onset and late-onset alzheimer's disease. Int J Geriatr Psychiatry. 2007;22:896-901.

11. Jahn H. Memory loss in Alcheimer's disease. Dialogues Clin Neurosci. 2013; 15(4): 445-454

12. Jacus JP. Awareness, apathy, and depression in Alzheimer's disease and mild cognitive impairment. Brain Behav. 2017 Apr; 7(4): e00661

13. Poreddi V, Thimmaiah R, Chandra R, BadaMath S. Bachelor of nursing students' attitude towards people with mental illness and career choices in psychiatric nursing. An Indian perspective. Invest Educ Enferm. 2015; 33(1): 148-154.
14. Schelp AO, Nieri AB, Filho PTH, Bales AM, MendesChiloff CL. Public awareness of dementia: A study in Botucatu, a medium sized city in the state of Sao Paulo, Brazil. Dement Neuropsychol. 2008 Jul-Sep; 2(3): 192-196

15. Alqahtani A, Alqahtani $M$, Zarbah A, Alahmari $T$, Alhazzani A. Public awareness, knowledge, and attituted toward Alzheimer's disease in Aseer region, Saudi Arabia community based cross sectional study. Neurology. 2017; 88 (16 Supplement)

16. Canadian study of health and aging: study methods and prevalence of dementia. CMAJ. 1994;150:899-913

17. Green RC, Cupples LA, Kurz A, Auerbach S et al. Depression as a risk factor for Alzheimer disease: the MIRAGE Study. Arch Neurol. 2003; 60(5):753-9.

18. Starkstein SE, Jorge R, Mizrahi R, Robinson RG. A prospective longitudinal study of apathy in Alzheimer's disease. J Neurol Neurosurg Psychiatry. 2006;77(1):8-11

19. Connell CM, Scott Roberts J, McLaughlin SJ. Public opinion about Alzheimer disease among blacks, hispanics, and whites: results from a national survey. Alzheimer Dis Assoc Disord. 2007; 21(3):232-40.

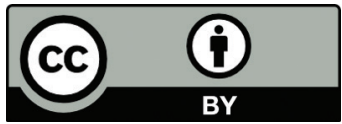

This work is licensed under a Creative Commons Attribution 